\title{
Dysphagia Caused by Giant Granuloma Arising from the Oropharyngeal Posterior Wall
}

\author{
Eun Kyung Jung (D), Bong-Jin Shin (D), Jongmin Kim (D), and Joon Kyoo Lee (D) \\ Department of Otolaryngology-Head and Neck Surgery, Chonnam National University Medical School, \\ Chonnam National University Hwasun Hospital, Hwasun, Korea
}

\section{연하곤란을 초래하는 구인두 후벽에서 발생한 거대육아종}

정은경, 신봉진, 김종민, 이준규

전남대학교 의과대학 화순전남대학교병원 이비인후과학교실

Granuloma is an uncommon benign disease that develops in the process of wound healing. Pharyngeal or laryngeal granuloma can be associated with gastric reflux, mechanical injury or trauma including intubation, voice abuse, or foreign body. 50-year-old female was transferred to our institute with a huge mass occupying the upper aerodigestive tract causing dysphagia. The patient has been suffering from a brain hemorrhage for several months and was kept in bed due to the quadriplegia with stuporous mental status, and was tracheotomized. On examination, the whole oropharynx and hypopharynx was covered by a smooth-surfaced soft big diffuse granular mass, which extended down to the upper trachea through the larynx. The huge granuloma was successfully removed with surgery and was found to have a pedunculating stalk on the oropharyngeal posterior wall with a small mucosal defect, suggestive of the origin of the mass. The defect was closed primarily after the cauterization. The patient is now followed up regularly without any recurrence of the disease.

Keywords Granuloma; Oropharynx; Laryngopharyngeal reflux; Wound and injuries; Deglutition disorders.

\section{서 론}

육아종은 상처 치유 과정에서 생길 수 있는 양성 병변이다. 인두나 후두에 발생하는 육 아종은 그 발생 기전에 대해서 아직 이견이 있으나[1], 위산의 역류[2-4], 기관삽관 등의 기계적인 손상[5,6], 위산의 역류와 기계적 손상의 혼합[7], 음성 남용[4], 혹은 이물질 반응 [8]과 연관되기도 한다. 수술적 절제가 표준적인 치료법[5]이지만 높은 재발률[9,10] 을 보이기도 한다.

본 연구자는 구인두 후벽에서 기시하여 인두 전체를 침범하고 후두 및 기관까지 연장 되어 내려와 연하곤란을 초래했던 거대 육아종 증례를 보고하면서 그 원인에 대한 고찰 을 하고자 한다.

\author{
Received October 24, 2020 \\ Revised November 13, 2020 \\ Accepted December 3, 2020
}

\section{Corresponding Author}

Joon Kyoo Lee, MD, PhD

Department of Otolaryngology-

Head and Neck Surgery,

Chonnam National University

Medical School,

Chonnam National University

Hwasun Hospital,

322 Seoyang-ro, Hwasun 58128, Korea

Tel +82-61-379-8190

Fax+82-61-379-8199

E-mail joonkyoo@jnu.ac.kr

\section{ORCID iDs}

Eun Kyung Jung (D) https://orcid.org/0000-0001-5371-3598 Bong-Jin Shin (D)

https://orcid.org/0000-0002-3110-756X Jongmin Kim (D)

https://orcid.org/0000-0002-6643-6531 Joon Kyoo Lee (D)

https://orcid.org/0000-0002-7542-9616

This is an Open Access article distributed under the terms of the Creative Commons Attribution Non-Commercial License (https://creativecommons.org/ licenses/by-nc/4.0) which permits unrestricted non-commercial use, distribution, and reproduction in any medium, provided the original work is properly cited. 


\section{증 례}

50 세 여자가 연하곤란을 호소하며 병원에 왔다. 환자는 9개 월 전 뇌출혈로 수술을 받았고 사지마비로 침상 생활을 하고 있었다. 의식은 혼미한 상태로 의사소통이 어려웠으며, 기관 절개술을 받고 튜브가 삽입되어 있었다. 위조루(gastrostomy) 를 통하여 주된 영양 공급을 하면서 구강 식이를 조금씩 병행 하던 환자로, 구강 식이가 전혀 안 되어 본 병원으로 전원되었 던 것이다.

신체 검사상, 백색 혹은 옅은 분홍색의 부드럽고 매끈한 표 면을 가진 여러 개의 엽을 가지는 미만성 육아성 종물이 구인 두 전체를 점유하고 있었다(Fig. 1). 이 병변은 전산화단층촬 영상 구인두뿐만 아니라 하인두를 포함한 인두 전체를 차지 하면서, 후두를 통과하여 기관까지 연장되어 내려와 있었다 (Fig. 2). 육안적인 관찰상 저명하게 부드러운 양성 병변으로 생각이 되었고, 또한 향후 철저한 제거 수술을 계획하고 있었

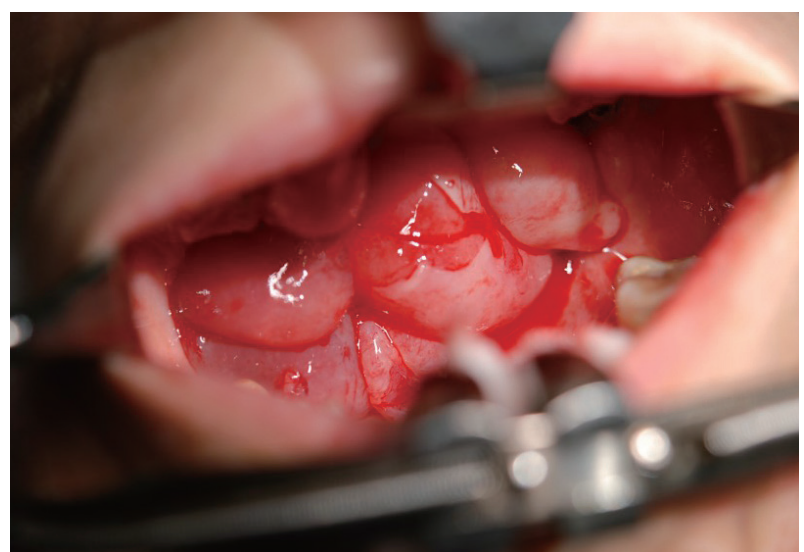

Fig. 1. Preoperative photograph exposed oropharynx with mouth gag demonstrating whitish to light pinkish soft smooth-surfaced diffuse lobulated granular mass occupying the whole oropharynx.
기에 술 전 조직검사는 시행하지 않았다.

전신마취하에 수술을 시행하였다. 환자를 앙아위(supine position)에서 개구기를 걸고 구인두를 노출시켰다. 종물이 구 인두와 하인두 후벽을 균등하게 모두 침범했을 것으로 예상 하였으나, 예상과 달리 하인두와 후두 병변은 실제 점막을 침범하지 않고 구인두 종물이 아래로 내려오는 형태(pedunculating)였다.

겸자를 이용하여 후두 및 기관과 하인두로 내려온 종물을 모두 제거하고 구인두 종물의 대부분을 제거하였다(Fig. 3). 그런데 구인두 부위에서는 대부분의 육아종이 제거된 후에 일부 조그마한 육아종이 후벽에 붙어 있어, 이 부위가 육아종 의 기시 부위임을 추정케 하였다. 구인두 후벽의 남은 부드러 운 육아종을 모두 제거하고 관찰한 결과, 약 $2 \mathrm{~cm}$ 정도의 세 로 방향의 점막 결손 부위가 있었으며 딱딱하고 주변 조직으 로 유착된 섬유 조직으로 변화되어 있었고, 이 부위가 바로 육아종의 기시부임을 알 수 있었다(Fig. 4).

결손 부위 병변을 전기소작술로 청소하고 양쪽 점막을 당

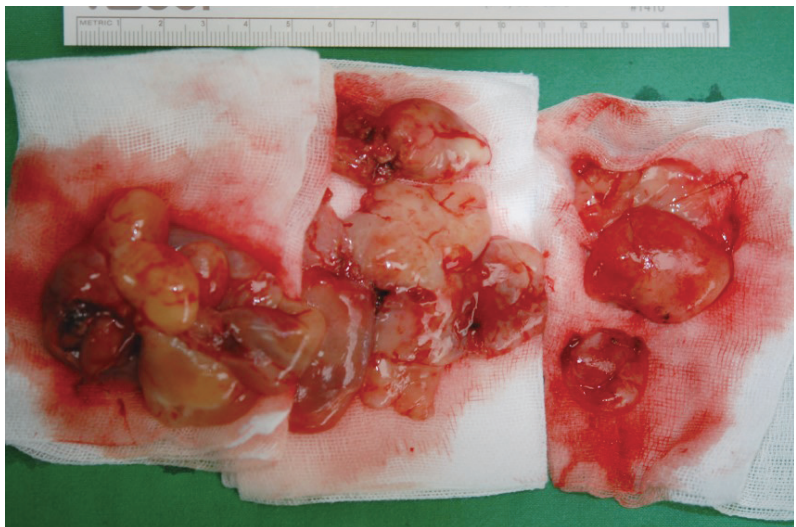

Fig. 3. Intraoperative photograph demonstrates removed soft granular mass in multiple pieces.
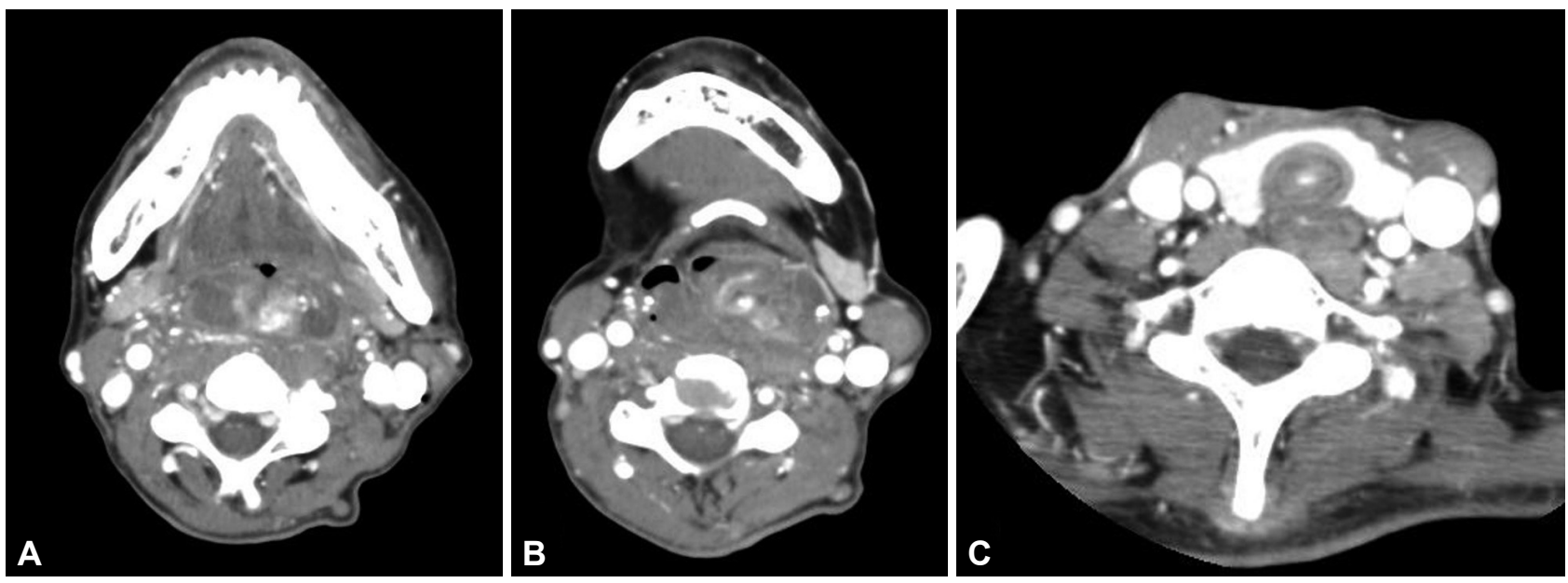

Fig. 2. Axial neck CT with enhancement demonstrates heterogeneously enhanced well-demarcated thin-walled elliptical lobulated mass occupying oropharyngeal posterior wall $(A)$ and hypopharyngeal posterior wall $(B)$, extending into the trachea just above tracheotomy stoma through the larynx (C). 
겨 일차 봉합을 시행하였다(Fig. 5). 절제된 종물은 조직검사 상 미세 혈관과 함께 섬유아세포의 증식과 염증성 세포의 침 윤을 보여 육아조직임이 확인되었다(Fig. 6).

환자는 퇴원 후 3주 만에 병원에 내원하였으며, 이 때 위조 루를 통한 영양 공급을 하고 있었지만 구강으로도 연식의 식 이를 하고 있었으며 연하 곤란이나 흡인은 호소하지 않았다. 탈관(decannulation)을 권유하였으나, 요양병원 의료진과 보 호자가 향후 환자 상태의 악화 등을 염려하여 유지하기로 하 였다. 3개월 후의 내시경 사진상 종물의 재발 없이 구인두 후 벽이 회복되었음을 확인하였다(Fig. 7).

\section{고 찰}

Shimazu 등[11]은 8주 연령의 쥐에서 위식도역류 모델을 만들었다. 즉, 위의 유문 괄약근(pyloric sphincter)을 외부에 서 묶고, 전위(forestomach)와 선 부위(glandular portion) 사

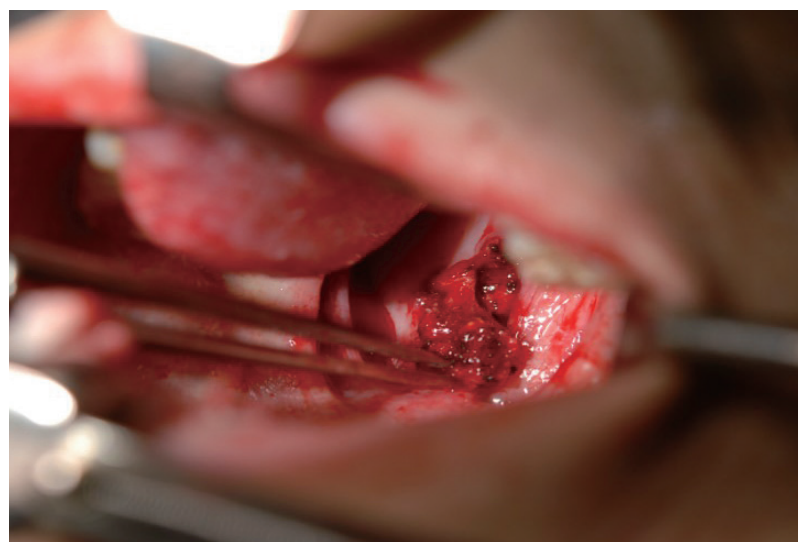

Fig. 4. Intraoperative photograph demonstrates about $2 \mathrm{~cm}$ sized longitudinal mucosal defect in the oropharyngeal posterior wall with hard, adhesive, and fibrotic bed, suggesting this region as the origin of the granuloma.
이에 있는 이행 부위(transitional region)를 실로 봉합하여 위 산이 식도로 역류하게 만들었다. 그런데 이 모델에서 위산 역 류에 의한 후두 점막의 염증 변화(점막의 비후, 혈관의 증식

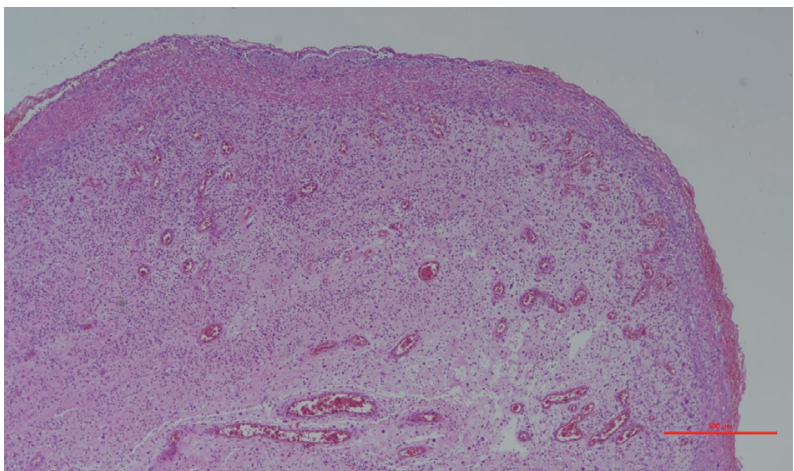

Fig. 6. Pathologic findings of the resected mass demonstrate small sized blood vessel and fibroblast proliferation with inflammatory cell infiltrations, indicating granulation tissue (hematoxylin and eosin staining, original magnification $\times 40$ ).

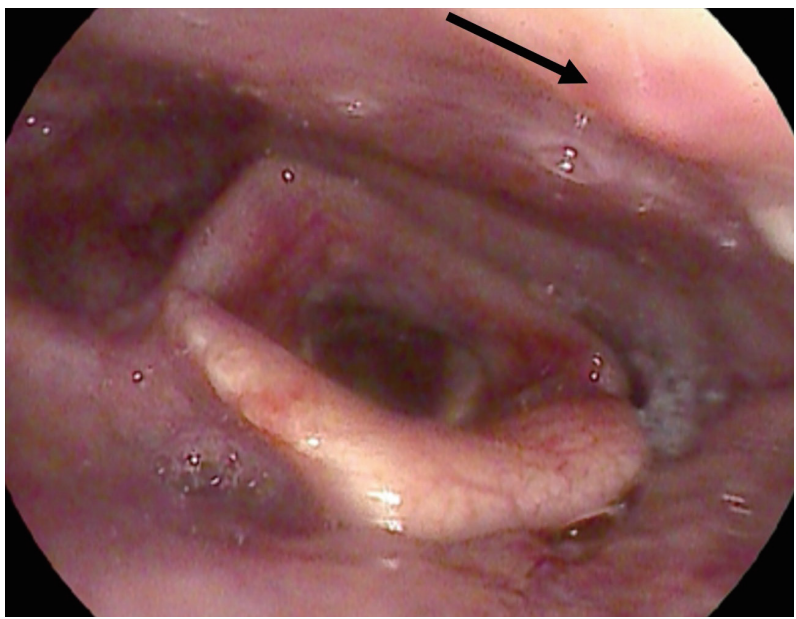

Fig. 7. Flexible laryngoscopy performed 3 months after the surgery demonstrates no recurred granuloma and healed oropharyngeal posterior wall (arrow) completely.

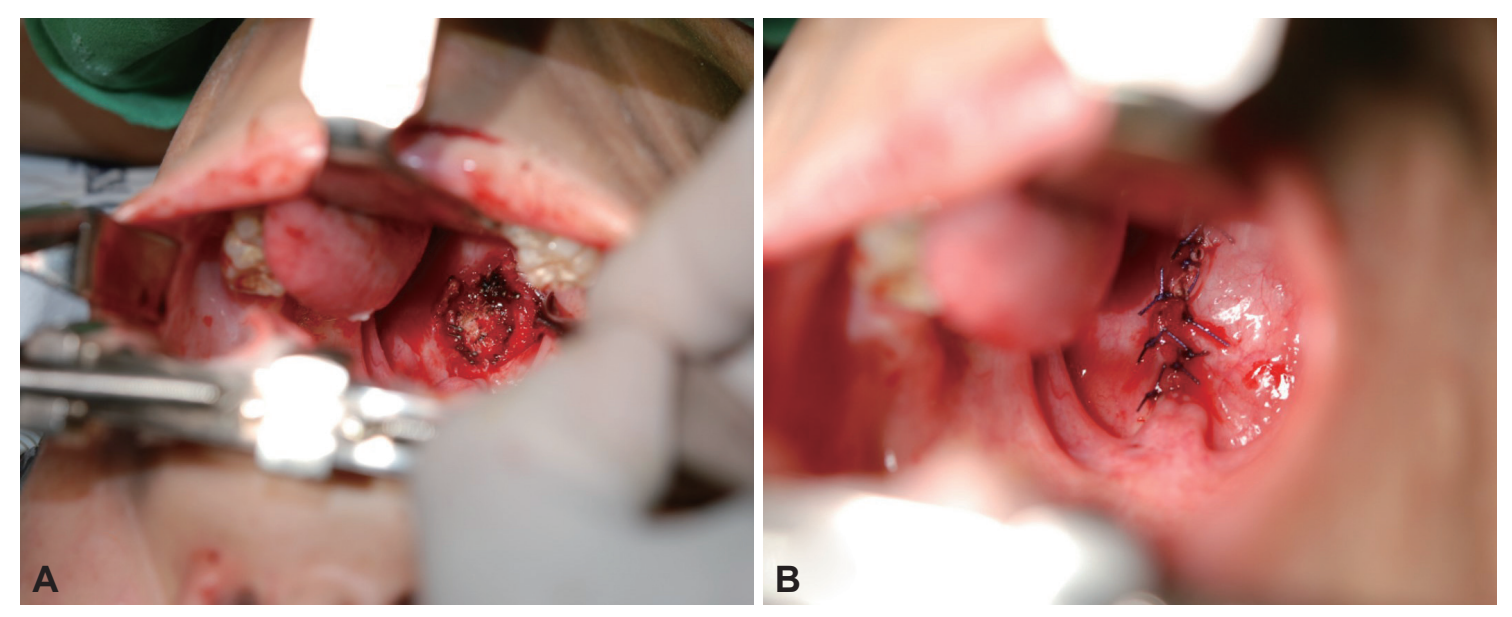

Fig. 5. Introperative photographs demonstrate treated defect of the oropharyngeal posterior wall with electrocauterization (A) and closed primarily (B). 
및 확장)는 있었으나 20주 동안의 관찰에도 불구하고 육아조 직은 발생하지 않았다고 하였다.

이들은 이 모델을 바탕으로 두 번째 연구를 시행하였는데 [7], 이번에는 쥐를 위식도역류를 만든 군과 대조군(복부 중앙 절개만 시행한 군), 두 군으로 나누고, 모든 군에서 플라스틱 막대기를 기관 안에 넣은 후 3초간 수직으로 세 번씩 움직여 서 성대 점막에 손상을 주었다. 2주가 지난 후 대조군에서는 후두 점막에 찰과상과 수포만 관찰되었을 뿐 육아조직은 형 성되지 않았으나, 위식도역류군에서는 $60 \%$ 의 쥐에서 육아조 직이 관찰되었고, 이것은 사람에게서 나타나는 육아조직과 조직학적 형태가 비슷하였다.

이 두 실험 결과를 토대로 이들은 위산 혹은 기계적인 손상 단독으로는 후두 점막에 육아조직을 형성시키기에 충분하지 않으며, 위산 역류와 기계적인 손상이 동반되었을 때 육아조 직이 형성된다고 보고하였다.

본 증례에서 거대 육아조직이 인두 후벽에 생긴 이유를 생 각해 보고자 한다. $\mathrm{Kim}$ 등[8]이 보고한 바와 같이 경추에 고 정된 금속에 대한 이물질 반응에 의한 것은 배제할 수 있다. 인두 후벽이 육아조직의 기시부라는 것을 감안했을 때, 어느 순간 이 부위 점막에 기계적인 손상이 있었을 것으로 추정된 다. 뇌출혈과 이를 치료하는 과정에서 기관삽관이나 다른 종 류의 시술 도중에서 인두 점막이 손상되었을 것이다. 그리고 장기간 침상 생활과 비위영양(nasogastric) 튜브 삽입으로 인 한 위산 역류가 있었을 것으로 추정할 수 있다. 따라서 인두 후벽의 점막 손상과 위산 역류 두 가지 인자가 동반되어 연하 곤란을 초래하는 거대한 육아조직이 발생되었을 것으로 사 료된다.

본 증례처럼 인두 후벽에 생긴 거대 육아종은 다른 문헌에 보고되지 않은 매우 드문 경우로 파악된다. 이에 반해 성대돌 기 육아종은 성인 남자에게서 흔히 발생하는 질환으로 주로 위식도역류, 삽관 손상, 그리고 음성 남용에 의해 생긴다. 주로 발성장애를 포함하여 다른 증상, 즉 히스테리성 증상(globus symptom), 애성, 기침, 연하통, 인후통을 수개월에서 수년에 걸 쳐 호소한다[9]. 기관삽관 후에 발생하는 경우에는 성인 여성 에서 흔하며, 일반적인 육아종과 달리 특징적으로 치료 후 잘 재발하지 않는다[12]. 감별해야 할 질환으로는 편평세포암, 혈관종, 카포시육종, 혹은 혈관육종 같은 혈관성 질환, 항상 균, 진균, 혹은 사르코이도증(sarcoidosis) 같은 감염과 연관 된 염증 반응에 의한 경우 등이다[13,14].

중심 단어: 육아종, 인두, 인후두역류, 상처, 연하 장애.
Acknowledgments

None.

Conflicts of Interest

The authors have no financial conflicts of interest.

Authors' Contribution

Conceptualization: Joon Kyoo Lee. Data curation: Jongmin Kim. Formal analysis: Bong-Jin Shin. Investigation: Jongmin Kim. Methodology: Bong-Jin Shin. Project administration: Joon Kyoo Lee. Resources: Eun Kyung Jung. Software: Bong-Jin Shin. Supervision: Joon Kyoo Lee. Validation: Bong-Jin Shin. Visualization: Eun Kyung Jung. Writing_original draft: Eun Kyung Jung. Writing_review \& editing: Joon Kyoo Lee. Approval of final manuscript: all authors.

\section{REFERENCES}

1. Song Y, Shi L, Zhao Y, Zhao D, Shi M, Deng Z. Surgical removal followed by radiotherapy for refractory vocal process granuloma. J Voice 2012;26(5):666.e1-5.

2. Delahunty JE, Cherry J. Experimentally produced vocal cord granulomas. Laryngoscope 1968;78(11):1941-7.

3. Tauber S, Gross M, Issing WJ. Association of laryngopharyngeal symptoms with gastroesophageal reflux disease. Laryngoscope 2002;112(5): 879-86.

4. Devaney KO, Rinaldo A, Ferlito A. Vocal process granuloma of the larynx-recognition, differential diagnosis and treatment. Oral Oncol 2005; 41(7):666-9.

5. Lee DH, Yoon TM, Lee JK, Lim SC. Surgical treatment outcomes of vocal process granuloma after endotracheal intubation. J Craniofac Surg 2018;29(4):e387-9.

6. Martins RH, Dias NH, Santos DC, Fabro AT, Braz JR. Clinical, histological and electron microscopic aspects of vocal fold granulomas. Braz J Otorhinolaryngol 2009;75(1):116-22.

7. Shimazu R, Kuratomi Y, Aoki S, Inokuchi A. Laryngeal granuloma in experimental rats with gastroesophageal reflux disease and mechanically injured vocal cord mucosa. Ann Otol Rhinol Laryngol 2014; 123(4):247-51.

8. Kim JH, Lee SK, Hong JH, Moon BJ, Lee JK. Retropharyngeal granulation: delayed complication of anterior cervical diskectomy and fusion in C2-3. World Neurosurg 2019;125:87-92.

9. Hoffman HT, Overholt E, Karnell M, McCulloch TM. Vocal process granuloma. Head Neck 2001;23(12):1061-74.

10. Mitchell G, Pearson CR, Henk JM, Rhys-Evans P. Excision and lowdose radiotherapy for refractory laryngeal granuloma. J Laryngol Otol 1998;112(5):491-3.

11. Shimazu R, Kusano K, Kuratomi Y, Inokuchi A. Histological changes of the pharynx and larynx in rats with chronic acid reflux esophagitis. Acta Otolaryngol 2009;129(8):886-92.

12. de Lima Pontes PA, De Biase NG, Gadelha EC. Clinical evolution of laryngeal granulomas: treatment and prognosis. Laryngoscope 1999; 109(2 Pt 1):289-94.

13. Wenig BM, Heffner DK. Contact ulcers of the larynx. A reacquaintance with the pathology of an often underdiagnosed entity. Arch Pathol Lab Med 1990;114(8):825-8.

14. Loehrl TA, Smith TL. Inflammatory and granulomatous lesions of the larynx and pharynx. Am J Med 2001;111(Suppl 8A):113S-7S. 